\title{
Analysis on the Impacts of COVID-19 on Food Industry and the Countermeasures
}

\author{
Liang Wang ${ }^{1}$ \\ ${ }^{1}$ Vanke Meisha Academy, Shenzhen, Guangdong, 518000, China \\ *Corresponding author. Email: wangliang@stu.vma.edu.cn
}

\begin{abstract}
As the epidemic continues to spread around the world, food shortages, food safety, and other food problems have become more and more obvious. Motivated by the huge impact of COVID-19 in all works of life, the obvious negative impact of COVID-19 on the food industry is shown. This research studies the negative impact of the epidemic on the food industry. By finding the impact of COVID-19 on different parts of the food industry. There are some influences that are analyzed that can be concluded: it is hard for someplace to maintain the stable agricultural production, it consumers cannot be wise to buy the food, it destroys the food system in the small countryside. The findings can help people wisely to defense against the next diseases like COVID-19.
\end{abstract}

Keywords: Covid-19, food industry, consumer, government

\section{INTRODUCTION}

From 2020 to 2021, COVID-19 has had a very large impact on the world. A variety of industries have been affected. In this article we will discuss the food industry. In the early stages of the COVID-19 outbreak, the food production industry caused by COVID-19 in some countries had a huge impact and caused food shortages. In the early days of an outbreak, people can often see panic about food shortages on the Internet. The epidemic highlighted the country's response to emergencies, and food is the top priority in people's lives. How to solve the food shortage has become the top issue in some countries. This article will discuss the root causes of food shortages from three aspects: the government, the people and the source of food, and give some suggestions to solve the problem. This article will discuss these questions: Why does food shortage only occur in some small countries? Why does the food shortage occur in the COVID-19? Does COVID-19 have any serious effects on food sources? The purpose of this article is to help people think rationally and clear the blind spots of food in the next disaster similar to COVID-19.

\section{COVID-19 CAUSE NEGATIVE EFFECT FOR FOOD INDUSTRY}

During the time of the COVID-19 outbreak, the food industry was greatly affected. In every process of transporting food, the source and consumers of the food have been affected by COVID-19. This article will discuss why you are affected by these effects and how to defend against them.

First of all, agriculture in small countries requires more human resources than agriculture in large countries. According to the article "The effects of the COVID-19 pandemic on food losses in the agricultural value chains in Africa: The Nigerian case study" by Funmilayo F.Ilesanmi, Olayinka S.Ilesanmi, "In Nigeria, agricultural labor is operated manually daily due to the unavailability of mechanized farming tools."[3] 


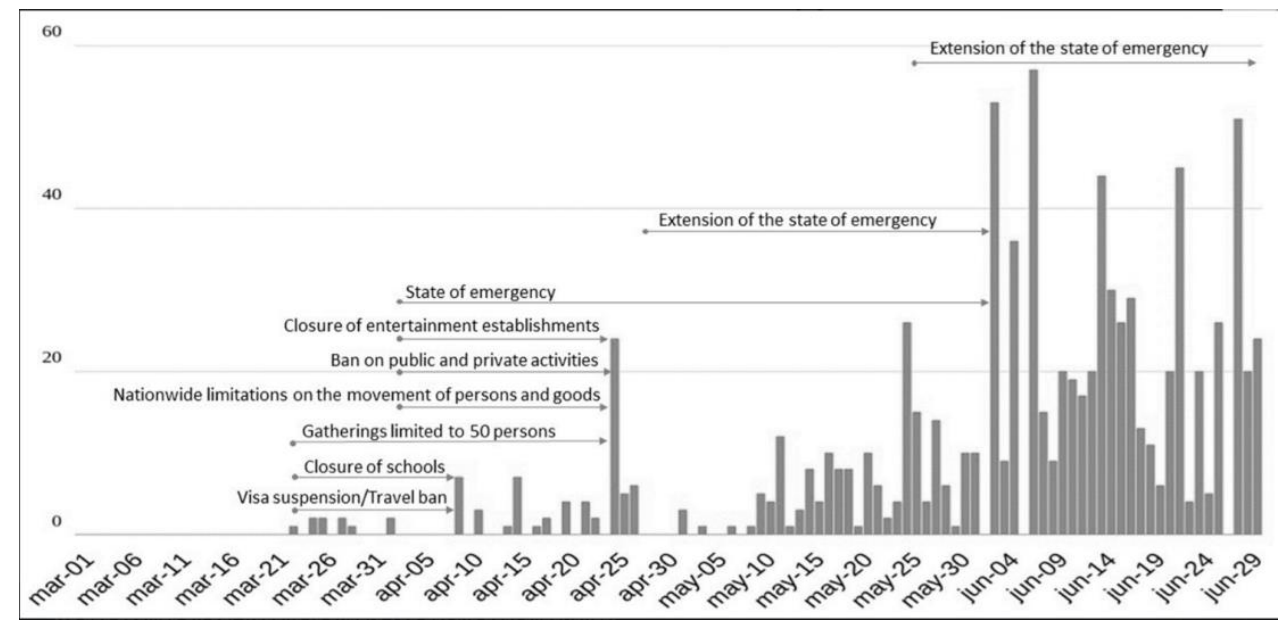

Figure 1 Daily cases and COVID-19 measures imposed by the Mozambican government [6].Source: The early food insecurity impacts of COVID-19. Nutrients, 12(7), 2096.

Due to the epidemic lockdown policy and behavioral restrictions during COVID-19, most of the agricultural productivity is lacking. Especially in some small countries, mechanical agriculture is not developed, and a lot of human resources are needed to grow farmland. The lack of manpower has caused the peak season of some plants to be missed, and the shelf life of some edible plants is very short. The food reserves of small countries cannot last until the next season, which leads to food shortages. According to the article article "COVID-19, Livestock Systems and Food Security in Developing Countries: A Systematic Review of an Emerging Literature" by Assem, Krautscheid,et al, "In particular, restrictions on public transport constrained farmers' access to input markets and output markets, as many of them transport inputs to the farm and production to markets by public transportation means.’'[5]

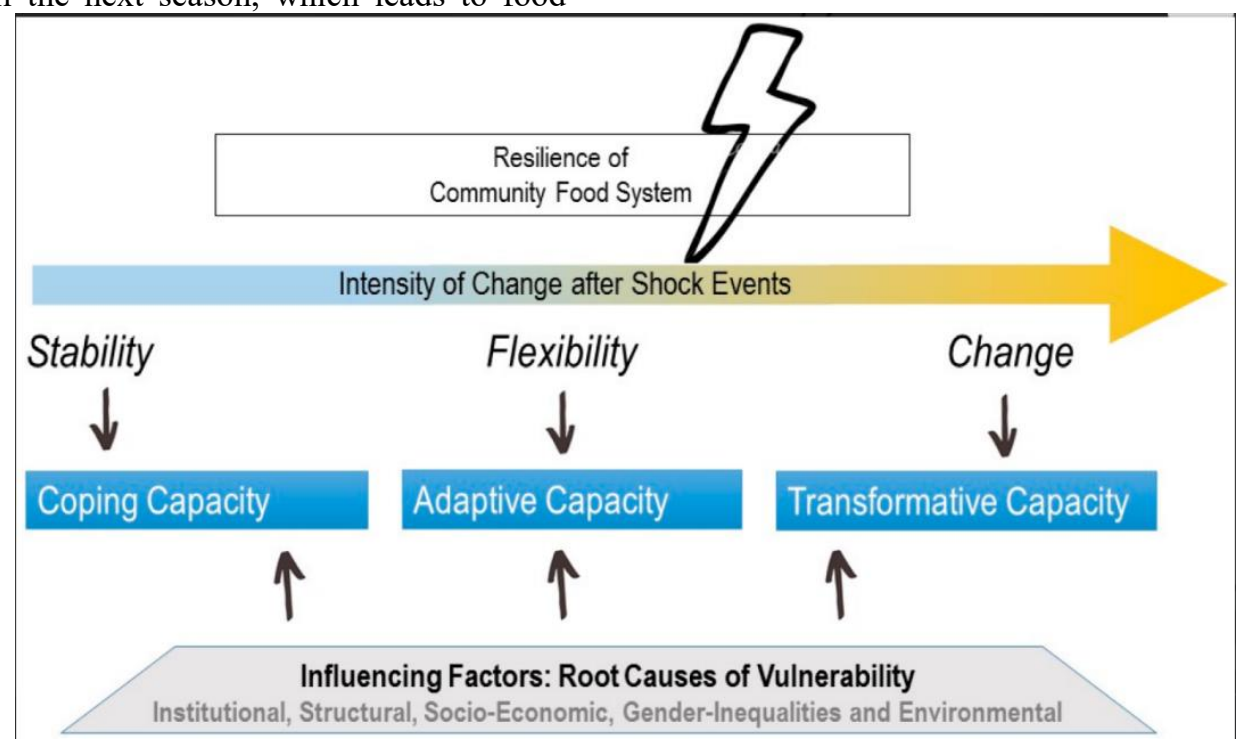

Figure 2 Resilience framework of local food systems impacted by shocks. Adapted from Paganini, N [7]

Because of the transportation restriction policy for COVID-19, this has made the transportation of food difficult. In addition to the impact on food transportation, a series of agricultural-related items such as seeds and fertilizers are also very difficult to transport. These factors limit agricultural production and lead to food waste.
Second, COVID-19 cause consumers cannot buy food calmly. According to the article "Unusual purchasing behavior during the early stages of the COVID-19 pandemic: The stimulus-organism-response approach" by Laato, Samuli, et al, “The initial rush for certain items caused shelves to empty, while a surplus was created for others.” [3] 


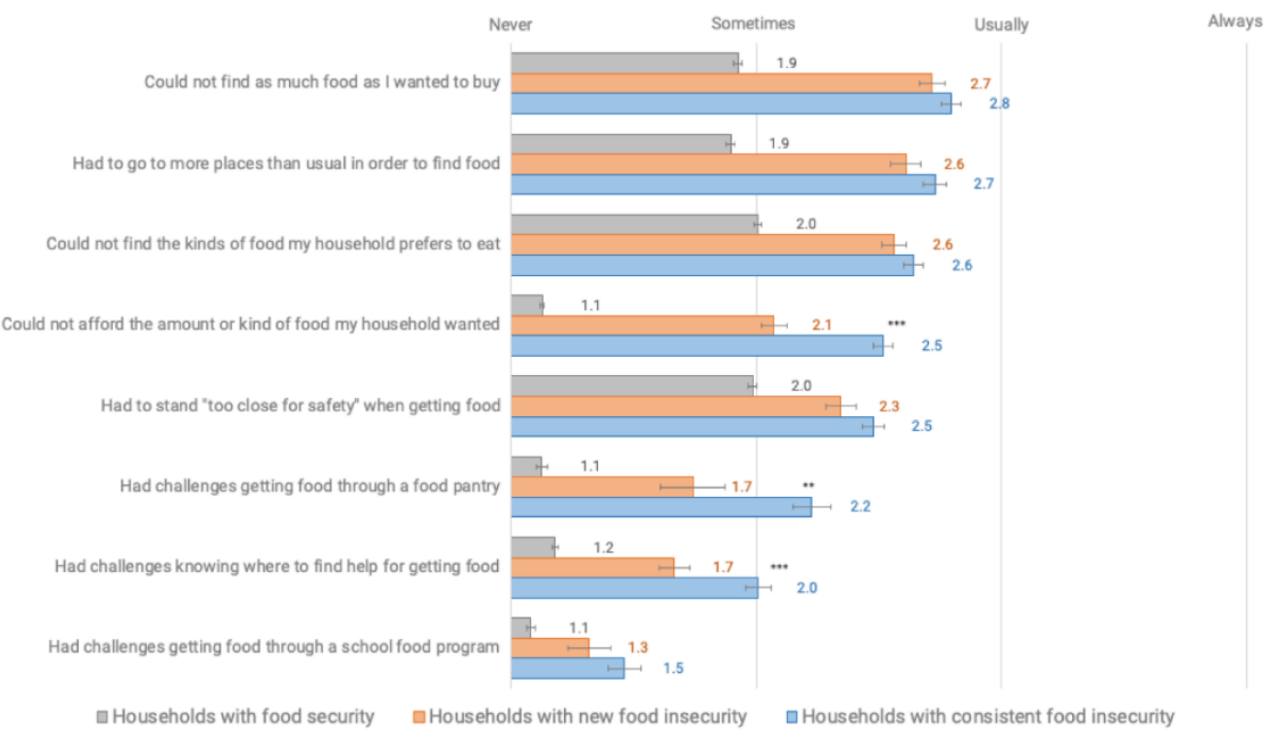

Figure 3 Average frequency of challenging food access situations since COVID-19 among respondents with household food security in a survey of Vermont households.

COVID-19 causes consumers can not to buy food wisely. A lot of companies bankrupted during COVID-19 and some people will be worried about food will become inadequate. COVID-19 will affect intentions to selfisolate and unusual purchases. Purchase self-efficacy reinforces the influence of COVID-19. Also, COVID-19 cause most food cannot be imported. It decreases the import food sales rate and it will cause people more worried about the food. It is a bad cycle. The government needs to make people believe it has the ability to control the food supply. The root of the problem is people do not believe in government.

Third, COVID-19 destroys the food system in the small town and countryside. To begin with, while some big cities can manage the food wisely and efficiently, but in the small countryside and town, the food is still a problem for them. According to M. Abdul-Razak, S. Kruse, et al, "To a large extent, COVID-19 did not reveal only the limits of our (national and international) health systems [2]; it also illustrated the fragility of our food systems, and how easily those can be disrupted. In sum, it sheds light on the central question of the resilience of food systems and its link to people' $s$ food and nutrition security." In the small town and countryside, the product is hard to work. They lack some of the fundamental equipment to work like electricity and road. Food is depending on the temperature and the other uncontrollable factors.

Also, in the small countryside and town, they can not solve the problem quickly. According to M. Abdul-Razak, $\mathrm{S}$. Kruse, et al, "In addition to those structural deficiencies, another large part of the current issues reflects directly the inability of the local/provincial food systems to respond and recover rapidly from the effects of shocks and stressors.[1]" When exposed to natural hazards such as droughts, floods, or human factors (local insecurity), these events seriously affect different actors involved in local regional food supply chains. This will stop its operation. They do not have any policy and behavior to face the problem, so COVID-19 can destroy their system easily. They need to have some countermeasure to face the problem.

The following are some suggestions on how to prevent food shortages: The government should increase food supervision. The government should give priority to food-related staff to receive vaccines. The government should promote the prevention and control of COVID-19 and eliminate people's panic about COVID-19. The government should promote agricultural mechanization while importing large quantities of foreign food. While transporting food, try to use isolation to prevent COVID19 . The government should promptly replace agricultural machinery to prevent similar situations.

\section{CONCLUSIONS}

The food shortage in COVID-19 has the following aspects: In some countries, agriculture requires a large number of people, but COVID-19 has prevented most people from investing in agricultural production. Due to a series of measures for COVID-19, it is also very difficult to transport a series of supplies related to agriculture. In the early stage of COVID-19, due to some media propaganda, people could not correctly judge whether there was a shortage of food. This led to stressful purchases, which eventually resulted in food shortages. In some remote areas, infrastructure is not in place and food management is lacking, which leads to food shortages. COVID-19 does not have a big impact on food, 
but it will affect people related to food. Before doing anything about food, we first need to consider the impact of COVID-19. The government should reform the food. Try to make the transportation of food reliable.

\section{ACKNOWLEDGMENT}

First of all, I would like to thank my parents for their support when I wrote the essay. Without them, there would be no me who I am now. Secondly, thanks to the teachers who nurtured me, because of your hard work, I have what I have gained today. Your encouragement and inspiration made me dare not slack in my studies. Besides put forward some ideas and methods when I searched for materials and wrote articles.

\section{REFERENCES}

[1].Campisi, Victoria. "How COVID-19 Is Impacting Eating." The Food Institute, 26 Oct. 2020, foodinstitute.com/focus/covid-impact-eating/.

[2].M. Abdul-Razak, S. Kruse, et al. "Resilience of Local Food Systems and Links to Food Security - A Review of Some Important Concepts in the Context of COVID-19 and Other Shocks." Food Security, Springer Netherlands, 1 Jan. 1970, link.springer.com/article/10.1007/s12571-02001076-1.

[3].Laato, Samuli, et al. "Unusual Purchasing Behavior during the Early Stages of the COVID-19 Pandemic: The Stimulus-Organism-Response Approach." Journal of Retailing and Consumer Services, Pergamon, 21 July 2020, www.sciencedirect.com/science/article/pii/S09696 98920304598.

[4].Ilesanmi, Funmilayo F., et al. "The Effects of the COVID-19 Pandemic on Food Losses in the Agricultural Value Chains in Africa: The Nigerian Case Study." Public Health in Practice, Elsevier, 5 Feb. 2021, Www.sciencedirect.com/science/article/pii/S26665 35221000124.

[5].Abu Hatab, Assem, et al. "COVID-19, Livestock Systems and Food Security in Developing Countries: A Systematic Review of an Emerging Literature." MDPI, Multidisciplinary Digital Publishing Institute, 11 May 2021, www.mdpi.com/2076-0817/10/5/586/htm.

[6].Niles, M. T., Bertmann, F., Belarmino, E. H., Wentworth, T., Biehl, E., \& Neff, R. (2020). The early food insecurity impacts of COVID19. Nutrients, 12(7), 2096.

[7].Paganini, N., Adinata, K., Buthelezi, N., Harris, D., Lemke, S., Luis, A., ... \& Stöber, S. (2020). Growing and eating food during the COVID-19 pandemic: farmers' perspectives on local food system resilience to shocks in Southern Africa and Indonesia. Sustainability, 12(20), 8556. 